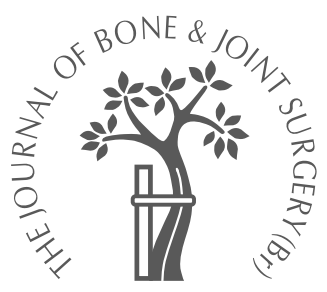

S. Gopal,

P. V. Giannoudis,

A. Murray,

S. J. Matthews,

R. M. Smith

From St James's

University Hospital,

Leeds, England

\title{
The functional outcome of severe, open tibial fractures managed with early fixation and flap coverage
}

We studied the outcome and functional status of 33 patients with 34 severe open tibial fractures (Gustilo grade IIIb and IIIc). The treatment regime consisted of radical debridement, immediate bony stabilisation and early soft-tissue cover using a muscle flap (free or rotational). The review included standardised assessments of health-related quality of life (SF-36 and Euroqol) and measurement of the following parameters: gait, the use of walking aids, limb-length discrepancy, knee and ankle joint function, muscle wasting and the cosmetic appearance of the limb. Personal comments and overall patient satisfaction were also recorded. The mean follow-up was $\mathbf{4 6}$ months (15 to 80 ).

There were 30 Gustilo grade IIlb fractures and and four grade IIIc fractures. Of the 33 patients, 29 had primary internal fixation and four, external fixation; $11(34 \%)$ later required further surgery to achieve union and two needed bone transport procedures to reconstruct large segmental defects. The mean time to union was 41 weeks (12 to 104). Two patients (6.1\%) developed deep infection; both resolved with treatment.

The mean SF-36 physical and mental scores were 49 and 62 respectively. The mean state of health score for the Euroqol was 68. Patients with isolated tibial fractures had a better outcome than those with other associated injuries on both scoring systems. Knee stiffness was noted in seven patients (21\%) and ankle stiffness in $19(56 \%)$; 12 patients $(41 \%)$ returned to work. Our results compare favourably with previous outcome measurements published for both limb salvage and amputation. All patients were pleased to have retained their limbs.

A severe, open fracture is the result of highenergy injury. It is assumed to be contaminated, and therefore may threaten the survival of the injured leg. ${ }^{1,2}$ The operative management is complex, time consuming and considered by many to create significant morbidity. ${ }^{3-7}$ Debate continues regarding the place of primary amputation. ${ }^{8-10}$ Many of the problems related to the unique anatomy of tibia with its vulnerable soft-tissue envelope. ${ }^{11}$

Traditionally open tibial fractures have been managed by debridement, often repeated, external fixation and delayed soft-tissue closure. ${ }^{12}$ Godina's ${ }^{13}$ proposed use of early, free, micro-vascular flaps to cover large contaminated wounds and the shift from external to internal fixation, ${ }^{14-16}$ has led to the development of a more radical approach to the management of these devastating injuries. An aggressive 'fix and flap' protocol, consisting of radical debridement, internal fixation and immediate or very early soft-tissue cover with muscle flaps, has been reported to give faster union times and lower infection rates ${ }^{17}$ but later functional data are not available.
The current study was conducted to determine the functional outcome of these complex injuries after a 'fix and flap' regime using established assessments of outcome by questionnaire. The effect of this treatment regime on gait, joint function and on the life-style and working ability of the patient was also studied.

\section{Patients and Methods}

We reviewed 33 patients (29 adults and four children) with 34 Gustilo grade IIIb or grade IIIc fractures from a group of 40 patients whose treatment with the fix and flap protocol was completed between 1996 and 2000. Three patients could not be reviewed because they had suffered severe concommitant head injuries, and four patients were lost to follow-up. There were 25 men, two boys, four women and two girls in the study group. The mean age for the adult group was 48 years (19 to 79).

The fix and flap protocol consists of a radical debridement of unhealthy soft tissues to the edge of the zone of injury, skeletal stabilisation (preferably internal) with an implant appropriate for the bony anatomy and immediate soft- 
tissue cover with a muscle flap. Four patients $(12 \%)$ had their fractures stabilised using external fixators at the primary receiving hospital before their transfer to our unit. The choice between a pedicle or a free muscle flap depended on the anatomy of the soft-tissue injury. If immediate soft-tissue reconstruction was not practical, our aim was to obtain soft-tissue cover within 72 hours of the injury.

After the surgery to the leg, early mobilisation, including 'toe touch' weight-bearing and joint motion was encouraged. Weight-bearing was increased as soon as possible, depending on the stability of the fracture and the signs of its healing. Rehabilitation was always supervised by a physiotherapist. Mobilisation was limited if there were additional injuries.

All patients were followed up until radiological union of the fractures were confirmed. Secondary bone stimulating procedures were performed early whenever problems of union were considered likely, as judged by the condition of the bone at the initial surgery and early progress. These secondary interventions included exchange nailing, autogenous bone grafting and bone transportation techniques.

All the patients in the current study were recalled for functional assessment by a senior research physiotherapist (AM) acting as an independent observer. She had not been involved with the post-operative rehabilitation of the patients. The mean follow-up at the time of final review was 46 months ( 15 to 80 ).

The patients were asked to complete two extensively used health outcome measurement questionnaires, namely the Short Form-36 (SF-36) ${ }^{18,19}$ and the Euroqol. ${ }^{20}$ Applicable to a wide range of health conditions, the Euroqol-5D (EQ-5D) provides both a compact descriptive profile and a single index value which can be used in the clinical and economic evaluation of health. ${ }^{21}$ It has been shown to be acceptable, valid and reliable in population studies and with other patient groups. ${ }^{22}$ It consists of five dimensions, namely mobility, self-care, usual activity, anxiety or depression and pain or discomfort. Each dimension has three levels representing degrees of perceived difficulty. In addition to these five dimensions, it incorporates a visual analogue score on which the patients are requested to rate their health on a scale from zero (worst imaginable) to 100 (best imaginable). A total of 245 theoretically possible health states can be defined and weights for these states are derived from a national representative survey of the UK population. ${ }^{23}$

The norms for the Euroqol are given as the percentages of the population surveyed, reporting problems for each of the five dimensions. ${ }^{24}$ Mobility, self-care and usual activity dimensions are reported as problematic by only $5 \%, 1 \%$ and $7 \%$ respectively of all respondents within the 20 to 29 age group. This rises to $40 \%$ for mobility, $7 \%$ for self-care, and $26 \%$ for usual activity in the 70 to 79 age group. More men report problems with usual activity than women. For self-care and usual activity the percentages are close for the two sexes in all age groups. Pain and activity or depression are noted by $16 \%$ and $13 \%$ respectively by the 20 to 29 age group. This rises to $56 \%$ and $25 \%$ for the 70 to 79 age group. More women report problems with these dimensions than men throughout the various age groups, with the exception of pain in the 60 to 69 age group. The figures for the mean health state score on the visual analogue scale for the various age groups is as follows: 87, 20 to 29 years; 86, 30 to 39 years; 85,40 to 49 years, 79,50 to 59 years; 80,60 to 69 years and 75,70 to 79 years.

Our physiotherapist independently calculated and analysed all the scores from these questionnaires. Analysis was carried out for the whole group, and mean scores were calculated in order to identify whether isolated injuries performed any differently from those with other associated injuries which affected rehabilitation. The scores were also analysed between patients who had primary union of the fracture and those that required secondary procedures and between patients who had an early flap cover compared with those whose cover was delayed more than 72 hours. Other parameters relevant to outcome status were also recorded. These included gait, the use of walking aids, limb length discrepancy, the range of movement of the knee and ankle joint, muscle wasting and strength, and comments about the cosmetic appearance of the injured limb. The patients were also asked about their employment history and overall personal satisfaction with limb salvage. The four children in the study were only assessed with regard to gait, joint function and the effect of their injury on education and physical activity. Data were analysed using a statistical package (Astute, The University of Leeds), by oneway analysis of variance.

\section{Results}

Of the 33 patients, 29 (30 fractures) were primarily treated by internal fixation and four by external fixation. Overall $11(34 \%)$ of the fractures required a delayed bone stimulating procedure. Two patients had bone transport to reconstruct large segmental defects. Two patients (6.1\%) developed deep infection; in both it resolved with debridement and systemic antibiotics. Other major limb fractures affected rehabilitation in 14 of the patients $(42 \%)$.

The fix and flap protocol aims to complete fixation of the fracture and soft-tissue cover at the same time, provided the patients and theatre conditions are conducive. Twelve of the 30 fractures $(40 \%)$ in the adult patients had a single fix and flap procedure; ten had immediate debridement and internal fixation but had their soft-tissue cover between 48 and 72 hours after the injury; eight free flaps could only be carried out more than 72 hours later because of severe head injury. We found that, in regard to bony union and infection rates, the patients who underwent immediate flap cover performed better (Table I).

The three patients, who could not be assessed for their functional outcome due to their severe head injuries, were all initially managed with ventilation, intracranial pressure 
Table I. Rates of union and infection (adult patients)

\begin{tabular}{lllll}
\hline Delay before flap cover (hrs) & Number of fractures & Time to bony union (wks) & Superficial infection & Deep infection \\
\hline$<24$ & 12 & 28.8 & 2 & 0 \\
24 to 72 & 10 & 35.5 & 2 & 1 \\
$>72$ & 8 & 43.11 & 3 & 1 \\
\hline
\end{tabular}

Table II. Summary of functional outcome (adult patients)

\begin{tabular}{|c|c|c|c|c|c|c|c|c|c|c|c|}
\hline Case & $\begin{array}{l}\text { Age } \\
\text { (yrs) }\end{array}$ & $\begin{array}{l}\text { Associated } \\
\text { injury } ¥\end{array}$ & ISS & $\begin{array}{l}\text { SF-36 } \\
\text { Physical }\end{array}$ & $\begin{array}{l}\text { SF-36 } \\
\text { Mental }\end{array}$ & $\begin{array}{l}\text { EQ-5D } \\
\text { health } \\
\text { score* }^{*}\end{array}$ & $\begin{array}{l}\text { EQ-5D } \\
\text { health } \\
\text { statet }\end{array}$ & $\begin{array}{l}\text { Knee } \\
\left.\text { flexion ( }{ }^{\circ}\right)\end{array}$ & $\begin{array}{l}\text { Ankle } \\
\text { plantar } \\
\text { flexion ( }{ }^{\circ} \text { ) }\end{array}$ & Limp‡ & $\begin{array}{l}\text { Loss of } \\
\text { length }(\mathrm{cm})\end{array}$ \\
\hline 1 & 34 & $Y$ & 14 & 47.6 & 60 & 21221 & 75 & 0 to 110 & 0 to 25 & $Y$ & 2.5 \\
\hline 2 & 65 & $Y$ & 13 & 67.5 & 67.9 & 21211 & 85 & 0 to115 & 0 to 20 & $Y$ & 0 \\
\hline 3 & 60 & $\mathrm{~N}$ & 9 & 24 & 34 & 21221 & 43 & -5 to 115 & 10 to 25 & $Y$ & 0 \\
\hline 4 & 37 & $N$ & 9 & 32.5 & 64.6 & 21222 & 50 & 0 to 130 & 10 to 20 & $\mathrm{~N}$ & 1.5 \\
\hline 5 & 34 & $Y$ & 25 & 40.2 & 38.2 & 22222 & 65 & 0 to 125 & 5 to 45 & $\mathrm{~N}$ & 0.5 \\
\hline 6 & 24 & $Y$ & 13 & 61 & 70.4 & 21221 & 55 & 0 to 120 & 5 to 45 & $\mathrm{~N}$ & 1.0 \\
\hline 7 & 52 & $\mathrm{~N}$ & 9 & 93.7 & 91 & 11111 & 100 & 0 to 135 & 0 to 45 & $\mathrm{~N}$ & 0 \\
\hline 8 & 35 & $\mathrm{~N}$ & 9 & 78.4 & 60.6 & 11122 & 80 & 0 to 125 & 5 to 45 & $\mathrm{~N}$ & 0.5 \\
\hline 9 & 53 & $Y$ & 13 & 9.2 & 11.4 & 21333 & 20 & 0 to 95 & 10 to 30 & $Y$ & 1.0 \\
\hline 10 & 26 & $\mathrm{~N}$ & 9 & 26.2 & 65 & 21231 & 75 & -10 to 130 & 5 to 45 & $Y$ & 0.5 \\
\hline 11 & 31 & $\mathrm{~N}$ & 9 & 85.2 & 100 & 11121 & 80 & 0 to 130 & 0 to 45 & $\mathrm{~N}$ & 0 \\
\hline 12 & 39 & $Y$ & 9 & 29.5 & 61.8 & 22222 & 75 & 0 to 120 & 0 to 15 & $Y$ & 0.5 \\
\hline 13 & 45 & $Y$ & 9 & 66.75 & 48.7 & 11211 & 95 & 0 to 120 & 5 to 45 & $\mathrm{~N}$ & 0 \\
\hline 14 & 71 & $\mathrm{~N}$ & 9 & 55.3 & 67.65 & 21221 & 75 & 0 to 110 & -10 to 30 & $\mathrm{~N}$ & 0.5 \\
\hline 15 & 59 & $\mathrm{~N}$ & 9 & 74 & 96.5 & 21121 & 50 & 0 to 120 & -10 to 30 & $Y$ & 2.0 \\
\hline 16 & 48 & $\mathrm{~N}$ & 9 & 74 & 96.5 & 11111 & 93 & 0 to 125 & -5 to 40 & $\mathrm{~N}$ & 0 \\
\hline 17 & 69 & $\mathrm{Y}$ & 9 & 34.25 & 31.4 & 22222 & 45 & 0 to 90 & -10 to 30 & $\mathrm{Y}$ & 0.5 \\
\hline 18 & 34 & $Y$ & 9 & 20.25 & 29.25 & 22332 & 50 & 0 to 125 & -5 to 50 & $Y$ & 0 \\
\hline 19 & 78 & $\mathrm{~N}$ & 13 & 41 & 62.5 & 21232 & 90 & 0 to 120 & 5 to 20 & $Y$ & 1.0 \\
\hline 20 & 30 & $\mathrm{~N}$ & 9 & 59.25 & 47.5 & 21221 & 70 & -10 to 125 & 0 to 50 & $Y$ & 0 \\
\hline 21 & 65 & $\mathrm{~N}$ & 9 & 44.5 & 81.75 & 21222 & 80 & 0 to 120 & 10 to 45 & $\mathrm{Y}$ & 1.0 \\
\hline 22 & 71 & $\mathrm{~N}$ & 9 & 84 & 96.5 & 21121 & 80 & 0 to 105 & 0 to 20 & $\mathrm{Y}$ & 1.0 \\
\hline 23 & 71 & $\mathrm{~N}$ & 9 & 21 & 33.3 & 22222 & 50 & 0 to 105 & 0 to 10 & $Y$ & 2.0 \\
\hline 24 & 37 & $\mathrm{~N}$ & 9 & 41.75 & 62.8 & 21222 & 50 & 0 to 115 & 5 to 35 & $Y$ & 1.0 \\
\hline 25 & 19 & $Y$ & 26 & 45.75 & 66.9 & 21222 & 80 & 0 to 135 & -5 to 50 & $Y$ & 1.5 \\
\hline $26(\mathrm{R})$ & 30 & $\mathrm{Y}$ & 9 & 39 & 72.25 & 22221 & 70 & 0 to 120 & 0 to 40 & $\mathrm{Y}$ & 0 \\
\hline $27(\mathrm{~L})$ & 30 & $Y$ & & 39 & 72.25 & 22221 & 70 & 0 to 110 & 0 to 30 & $Y$ & 4.0 \\
\hline 28 & 59 & $Y$ & 18 & 68.5 & 78.5 & 21212 & 51 & 0 to 105 & 10 to 20 & $Y$ & 0 \\
\hline 29 & 70 & $\mathrm{Y}$ & 22 & 38.25 & 60.5 & 21221 & 70 & 0 to 65 & 5 to 15 & $Y$ & 0.5 \\
\hline 30 & 32 & $Y$ & 9 & 24.25 & 39.1 & 22222 & 70 & -10 to 110 & 5 to 15 & $Y$ & 4.0 \\
\hline
\end{tabular}

monitoring and debridement with external fixation of the fracture. Internal fixation with unreamed nails and flap cover was carried out as soon as neurological monitoring allowed, four, seven and 12 days after injury respectively. The head injuries were severe enough to render these patients permanently incapacitated; we have no evidence that our management, carried out with close neurosurgical supervision and advice, adversely affected the outcomes in these patients. The fractures united at 22, 18 and 31 weeks respectively with the latter two patients developing superficial soft-tissue infection which responded to dressings and antibiotics.

The functional assessments are summarised in Table II. The mean EQ-5D health score was 68/100. The majority of the patients $24(82.7 \%)$ and $23(79.3 \%)$ reported some restriction of mobility and usual activity, respectively. Anxiety was reported by $20(68.8 \%)$ of the patients, whilst four
$(13.4 \%)$ said they were depressed. Pain was a problem for $13(44.8 \%)$ of the patients. Most, however, were able to look after themselves well but seven $(24 \%)$ reported problems with self-care.

Using the SF-36 System, the mean physical score was 49 (21 to 93.7), and the mean mental score 62 (11.4 to 100). The mean component scores for each of the eight dimensions were as follows: physical function, 48.7 (0 to 100); role physical, 41.7 (0 to 100 ); bodily pain, 51.62 (20 to 100); general health, 49.75 (0 to 87 ); vitality, 47.75 (15 to 95); social functioning, 72.71 (12.5 to 100$)$; role emotional, 62.05 (0 to 100 ); mental health, 63.86 (8 to 100 ). Individual SF-36 scores with age and sex norms are given in Tables III and IV. Patients scored more highly in both the physical and mental function categories when they had an isolated tibial fracture and when they had primary bone healing, but these results were not related to early soft-tissue cover 
Table III. SF-36 health outcome scores in adult patients (SD)

\begin{tabular}{|c|c|c|c|c|c|c|c|c|c|}
\hline Case* & Age & PF & $\mathbf{R P}$ & BP & GH & V & SF & RE & MH \\
\hline 18 to 24 & norms M & $93(17)$ & $92(22)$ & $87(18)$ & $72(20)$ & $66(17)$ & $90(16)$ & $83(31)$ & 75 (15) \\
\hline 6 & 24 & 80 & 50 & 52 & 62 & 35 & 66.6 & 100 & 80 \\
\hline 18 to 24 & norms $\mathrm{F}$ & $90(16)$ & $89(26)$ & $82(21)$ & $72(20)$ & $60(19)$ & $86(20)$ & 79 (33) & 70 (17) \\
\hline 25 & 19 & 60 & 25 & 41 & 57 & 25 & 100 & 66.6 & 76 \\
\hline 25 to 34 & norms $\mathrm{M}$ & $94(14)$ & $92(23)$ & $88(18)$ & 77 (18) & $65(17)$ & $91(16)$ & $87(28)$ & 76 (15) \\
\hline 10 & 26 & 50 & 0 & 32 & 25 & 25 & 75 & 100 & 80 \\
\hline 20 & 30 & 75 & 75 & 62 & 25 & 35 & 50 & 66.6 & 40 \\
\hline $26(\mathrm{R})$ & 30 & 25 & 50 & 51 & 30 & 50 & 75 & 100 & 64 \\
\hline 27 (L) & 30 & 25 & 50 & 51 & 30 & 50 & 75 & 100 & 64 \\
\hline 11 & 31 & 90 & 100 & 64 & 87 & IDt & 100 & 100 & Id \\
\hline 30 & 32 & 25 & 0 & 41 & 27 & 55 & 37.5 & 0 & 64 \\
\hline 1 & 34 & 35 & IDt & 41 & 67 & 45 & 75 & IDt & 60 \\
\hline 5 & 34 & 75 & 0 & 41 & 45 & 55 & 50 & 0 & 48 \\
\hline 18 & 34 & 25 & 0 & 31 & 25 & 15 & 50 & 0 & 52 \\
\hline 35 to 44 & norms M & $92(15)$ & $90(26)$ & $86(20)$ & 74 (19) & 64 (19) & $91(17)$ & $86(29)$ & 75 (16) \\
\hline 4 & 37 & 65 & 0 & 40 & 25 & 40 & 62.5 & 100 & 56 \\
\hline 24 & 37 & 70 & 50 & 32 & 15 & 50 & 33.3 & 100 & 68 \\
\hline 12 & 39 & 35 & 0 & 41 & 42 & 50 & 62.5 & 66.6 & 68 \\
\hline 35 to 44 & norms F & 89 (16) & 87 (29) & $79(22)$ & $74(20)$ & $58(20)$ & $88(21)$ & $80(34)$ & 72 (18) \\
\hline 8 & 35 & 90 & 100 & 100 & 25.6 & 40 & 66.6 & 100 & 56 \\
\hline 45 to 54 & norms M & $88(17)$ & $88(28)$ & $82(22)$ & $72(20)$ & $63(20)$ & $90(19)$ & $86(30)$ & 76 (17) \\
\hline 13 & 45 & 20 & 75 & 100 & 72 & 35 & 62.5 & 33.3 & 64 \\
\hline 16 & 48 & 55 & 100 & 84 & 57 & 90 & 100 & 100 & 96 \\
\hline 7 & 52 & 100 & 100 & 100 & 75 & 80 & 100 & 100 & 84 \\
\hline 9 & 53 & 15 & 0 & 22 & 0 & 25 & 12.5 & 0 & 8 \\
\hline 55 to 64 & norms M & $80(22)$ & 79 (36) & $79(24)$ & $68(23)$ & $63(20)$ & $87(30)$ & $86(30)$ & 78 (17) \\
\hline 15 & 59 & 55 & 100 & 84 & 57 & 90 & 100 & 100 & 96 \\
\hline 28 & 59 & 55 & 100 & 72 & 47 & 50 & 100 & 100 & 64 \\
\hline 3 & 60 & 25 & 0 & 31 & 40 & 30 & 50 & 0 & 56 \\
\hline
\end{tabular}

PF - physical function; RP - role physical; BP - bodily pain; GH - general health; V - vitality; SF - social functioning; $\mathrm{RE}$ - role emotional; $\mathrm{MH}$ - mental health; $\mathrm{M}$ - male; $\mathrm{F}$ - female

* patients case numbers are the same as listed in Table I

† incomplete data

Table IV. SF-36 health outcome scores for patients over 65 years (SD)

\begin{tabular}{llllllllcc}
\hline Case $^{*}$ & Age & PF & RP & BP & GH & V & SF & RE & MH \\
\hline 65 to 69 & norms M & $67(30)$ & $57(43)$ & $68(28)$ & $57(24)$ & $59(23)$ & $79(29)$ & $67(42)$ & $75(19)$ \\
2 & 65 & 55 & 30 & 84 & 82 & 45 & 100 & 66.6 & 60 \\
21 & 65 & 45 & 25 & 41 & 67 & 55 & 100 & 100 & 72 \\
17 & 69 & 5 & 50 & 20 & 62 & 20 & 66.6 & 0 & 40 \\
70 to 74 & norms M & $62(30)$ & $48(43)$ & $66(28)$ & $56(24)$ & $56(22)$ & $75(30)$ & $62(44)$ & $74(19)$ \\
29 & 70 & 55 & 0 & 41 & 57 & 70 & 66.6 & 33.3 & 72 \\
23 & 71 & 0 & Id & 42 & Id & Id & 66.6 & 0 & Id \\
70 to 74 & norms F & $56(29)$ & $42(43)$ & $60(28)$ & $56(23)$ & $52(22)$ & $73(30)$ & $56(44)$ & $68(20)$ \\
14 & 71 & 40 & Id & 51 & 75 & 45 & 75 & 66.6 & 84 \\
22 & 71 & 65 & 100 & 84 & 87 & 85 & 100 & 100 & 100 \\
75 to 79 & norms M & $58(30)$ & $48(42)$ & $64(29)$ & $56(23)$ & $54(22)$ & $70(32)$ & $55(44)$ & $74(19)$ \\
19 & 78 & 25 & Id & 21 & 77 & 95 & 75 & 0 & 80 \\
\hline
\end{tabular}

PF - physical function; RP - role physical; BP - bodily pain; GH - general health; V - vitality; SF - social functioning; $\mathrm{RE}$ - role emotional; $\mathrm{MH}$ - mental health; $\mathrm{M}$ - male; $\mathrm{F}$ - female

* patients case number are the same as listed in Table I

Table V. Functional outcome for isolated versus associated injuries (range)

\begin{tabular}{|c|c|c|c|c|c|}
\hline Groups & Age mean/med & ISS* mean/med & PCSt mean/med & MCS $¥$ mean/med & EQ-5D mean/med \\
\hline Isolated $(n=15)$ & $51.4 / 52$ years ( 26 to 78 ) & $9.2 / 9$ (9 to 13$)$ & $55.6 / 55.3$ (21 to 93$)$ & $68.9 / 65$ (33 to 100$)$ & $71 / 75$ (43 to 100$)$ \\
\hline Associated $(n=14)$ & $46.3 / 34.5$ years ( 24 to 78 ) & $14.4 / 13$ (9 to 26$)$ & $42.3 / 40 \quad$ (9.2 to 67$)$ & $52.5 / 60.1$ (11 to 78$)$ & $64.7 / 70$ (20 to 95$)$ \\
\hline $\mathrm{p}$ value & 0.1 & 0.001 & 0.13 & 0.09 & 0.3 \\
\hline
\end{tabular}

* injury severity score

† physical capacity score

‡ mental capacity score 
Table VI. Functional outcome for primary versus secondary union (range)

\begin{tabular}{lllll}
\hline Groups & Age mean & PCS* mean & MCS t mean & EQ-5D mean \\
\hline Primary $(n=16)$ & 47.1 years (30 to 78) & $53.6(20$ to 85) & 58.9 (29.2 to 100) & 73.3 (45 to 95) \\
Secondary $(n=13)$ & 45.6 years (19 to 71) & $43.7(9.2$ to 93.7) & 63.5 (11 to 96) & $61.4(20$ to 100) \\
p value & 0.7 & 0.22 & 0.32 & 0.13 \\
\hline
\end{tabular}

* physical capacity score

$\dagger$ mental capacity score

Table VII. Functional outcome for early ( $<72 \mathrm{hrs}$ ) versus ( $>72 \mathrm{hrs}$ ) flap cover (range)

\begin{tabular}{lllll}
\hline Group & Age mean & PCS* mean & MCS + mean & EQ-5D mean/med \\
\hline Early flap $(\mathrm{n}=21)$ & $45.6 \quad(19$ to 78$)$ & 45.2 (9.2 to 78.4) & 56.6 (11.4 to 96.5) & $65.5 / 70$ (20 to 95) \\
Delayed flap N = 8 & $48.5 \quad(30$ to 71) & 59.7 (32.5 to 93) & 72.4 (38.2 to 100) & $74.3-7.5$ (50 to 100) \\
p value & 0.7 & 0.1 & 0.17 & 0.35 \\
\hline
\end{tabular}

* physical capacity score

† mental capacity score

(Tables V to VII). However, these differences did not reach statistical significance $(\mathrm{p}>0.05)$.

Specific modalities. Twenty patients $(61 \%)$ had a limp and all of them had slight shortening of the affected limb (mean, $1.35 \mathrm{~cm} ; 0.54$ to 4). In 12 of these the limp either resolved or improved with the correction of the limb-length discrepancy. The others whose limp persisted despite correction, had an antalgic gait attributed to a different cause. Nine patients $(27 \%)$ used a walking stick and four $(12 \%)$ used an orthosis.

Joint function. In seven limbs $(21 \%)$ there was a fixed flexion deformity of the knee measuring $5^{\circ}$ to $10^{\circ}$; three $(9 \%)$ had less than $100^{\circ}$ of flexion. The mean flexion in the knees was $116^{\circ}$.

There was an equinus deformity in one ankle $\left(5^{\circ}\right)$ but plantar flexion was reduced in 19 patients $(8 \%)$. The mean loss of plantar flexon was $17^{\circ}$.

Muscle bulk and power. Sixteen patients $(48 \%)$ had a mean thigh wasting of $1.5 \mathrm{~cm}(0.5$ to 4.5$)$ and 14 patients $(42 \%)$ had a mean calf wasting of $1.5 \mathrm{~cm}(0.5$ to 3.5$)$ on the affected side.

All had at least MRC power grade 4 in the muscle of the thigh and calf, with the exception of one patient who had neurological sequelae from his head injury.

Employment history. Of the 29 adults, $12(41 \%)$ returned to work; of these, seven $(24 \%)$ returned to their original employment and two others returned with minor modifications to their original professional environment; three changed their jobs to lighter, less physically demanding work.

Children. The mean age of the four children, at the time of their assessment, was 13 years (8 to 15 ). Two had Gustilo grade IIIc injuries. All had normal joint function and attended full time education and physical activities at school. Two had limb shortening $(1.5$ and $2 \mathrm{~cm}$ respectively) but all had normal growing limbs with no increasing deformity. Three missed school for eight, 11 (grade IIIb injuries) and 21 weeks (grade IIIc) respectively. The other child with a grade IIIc injury returned to full time education by repeating a school year. She had been absent from school for more than half of the academic year as she required a further procedure for nonunion of a defect in a segmental fracture.

Cosmetic appearance. Half of the patients said that the appearance of the limb was acceptable. However, only one adult female patient was really satisfied with the appearance of her injured limb. In spite of various problems faced by the patients all expressed their pleasure at having retained their own leg.

\section{Discussion}

Severe open fractures of the tibia are a major challenge, and many patients ultimately undergo amputation. ${ }^{5,25,26} \mathrm{~A}$ major advance in management came in 1973 with the introduction of microvascular free flaps by Daniel and Taylor. ${ }^{27}$ This reduced the time to union and the incidence of infection. ${ }^{28,29}$ Godina $^{13}$ brought a new dimension to the treatment of these injuries by advocating the use of free tissue transfer very early, within five days of the injury. Effective internal fixation facilitates soft-tissue cover and secondary bone grafting, together with improved patient compliance. ${ }^{14,15,30,31}$ We have successfully combined these two approaches in our unit to take Godina's concept to the extreme, advocating where possible immediate soft-tissue and bony reconstruction. ${ }^{16,17}$ We believe that bringing healthy muscle into the fracture site is essential and that it also introduces important cellular and humoral elements to the healing process which have yet to be defined.

In this study, the mean SF-36 physical and mental scores of 49 and 62 respectively are low compared with the normal population, reflecting the severity of these injuries. Saving life and limb takes the highest priority, followed by rehabilitation. The psychological impact of trauma is often neglected. Pain is a major precipitating factor for psychological disturbance. ${ }^{32}$ The mean pain score for the nine patients with a mean mental score $<60$ was 43.3 whereas that for the other 20 patients was 57.8. Patients scored better if they had an isolated tibial fracture and achieved 
primary bone union but this observation on both the SF-36 and the EQ-5D questionnaires did not reach statistical significance, probably due to a type II error on small numbers. On the other hand, of the 22 fractures with early flap cover, $12(54.5 \%)$ had other significant lower limb injuries whereas in the group whose flap cover was completed late, only two of eight $(25 \%)$ had other lower limb injuries. It is our impression that the poorer functional outcome in this group is due to the compounding effect of the other injuries, especially that to the CNS, despite better fracture union rates and no incidence of osteomyelitis.

The mean ranges of movement for the knees and ankles in our study again correlates with similar studies where open tibial fractures were treated by internal fixation. ${ }^{14,15,31}$ Our re-employment rate $(41 \%)$ is lower than that reported by Arangio, Shannon and Reed ${ }^{33}(76 \%)$ and Francel et $\mathrm{al}^{34}(67 \%)$. It is possible that the higher mean age of our study group (48 years) affected this outcome criterion.

All four children in our study did well, both with regard to healing and eventual functional outcome despite devastating III-C injuries in two. All went back to full time education and have regained their pre-injury levels of physical activity; all had excellent function and growing limbs. Previous reports have noted similar problems with a mean of 4.1 months of missed school, a third having to repeat a year and a similar number suffering from chronic pain. ${ }^{35}$ Buckley et $\mathrm{a}^{36}$ found delayed union and tibial overgrowth to be major problems with open fractures in children, but they recorded spontaneous correction of malunion in three of four children.

Modern techniques have made limb salvage possible but many have expressed scepticism regarding the long-term disability associated with limb salvage. Several authors have reported a quicker time to recovery and reduced longterm disability with amputation ${ }^{9,10}$ although others disagree. ${ }^{37,38}$ Dougherty ${ }^{39}$ described the functional outcome of transtibial amputees from the Vietnam War. All had been treated in the same specialist centre with intensive multidisciplinary involvement at every stage from amputation to prosthetic training. The SF-36 scores for each of the eight components are better than in our study. However, their patients were very different from ours in that they were young highly trained military personnel. Their mean length of follow-up was 28 years, giving more time to adapt to life with the prosthesis. The importance of amputation at a single centre is emphasised by poorer results when other war veterans undergo various aspects of treatment in different centres. ${ }^{40}$

Our study does not confirm whether limb salvage may be better or worse than amputation with regard to the functional outcome. However, studies comparing limb salvage with amputation suggest similar or better results for limb salvage. We would also note that comparing the function of below-knee amputees with salvage patients is not always appropriate. Many of our patients had such severe soft- tissue injuries that the alternative would often have been an above, rather than below-knee amputation. Bosse et $\mathrm{a}^{41}$ suggest that reconstruction gives outcomes which are equivalent to those of amputation at two-year follow-up; Hertel, Strebel and Ganz, ${ }^{42}$ report a significantly higher number of amputees required retraining and long-term invalidity pensions compared with patients who had their limbs salvaged. ${ }^{33}$ There are also greater psychological implications for amputation. Hoogendoorn and Van der Werken ${ }^{37}$ found a mean functional impairment of the lower extremity in patients with limb salvage of $17.6 \%$ compared with $73.5 \%$ for amputees although they did not find significant differences between the two groups, using the Nottingham Health Profile (NHP) and the SF-36 scores. Both of these groups had poorer scores than a healthy reference group. Dagum et $\mathrm{al}^{38}$ found that the scores for their injured group were lower than those for patients with serious medical illnesses irrespective of the treatment (salvage or amputation). They also noted significantly lower SF-36 physical scores for primary and secondary amputees (28 for amputees versus 38 for salvage). In common with Dagum et al's study, ${ }^{38}$ all our patients expressed their satisfaction at retaining their limbs. The SF-36 scores in our study compare well with the above-mentioned studies.

Thus, this study and others shows that limb salvage remains a reasonable option. However, although specialist reconstruction can be rewarding one should not under-estimate the difficulties in coping with these devastating injuries.

No benefits in any form have been received or will be received from a commercial party related directly or indirectly to the subject of this article.

\section{References}

1. Gustilo RB, Anderson JT. Prevention of infection in the treatment of one thousand and twenty five open fractures of the long bones. J Bone Joint Surg [Am] 1976;58-A: 453-9.

2. Gustilo RB, Mendonza RM, Williams DN. Problems in the management of type III (severe) open fractures: a new classification of type III open fractures. J Trauma 1984; 24:742-6.

3. Hansen ST Jr. The type-IIlc tibial fracture: salvage or amputation. J Bone Joint Surg [Am] 1987;69-A:799-800.

4. Georgiadis GM, Behrens FF, Joyce MJ, Earle S, Simmons AL. Open fractures with severe soft tissue loss: limb salvage compared with below-the-knee amputation. J Bone Joint Surg [Am] 1993;75-A:1431-41.

5. Fairhurst MJ. The function of below knee amputees versus the patient with salvaged grade-III tibial fracture. Clin Orthop 1994;301:227-32.

6. Edwards CC, Simmons SC, Browner BD, Weigel MC. Severe open tibial fractures: results treating 202 injuries with external fixation. Clin Orthop 1988;230: 98-115

7. Chan KM, Leung YK, Cheng JC, Leung PC. The management of type III open tibial fractures. Injury 1984;16:157-65.

8. Caudle RJ, Stern PJ. Severe open fractures of the tibia. J Bone Joint Surg [Am] 1987;69-A801-5

9. Blick SS, Brumback RJ, Lakatos R, Poka A, Burgess AR. Early prophylactic bone grafting of high-energy tibial fractures. Clin Orthop 1989;240:21-41.

10. Court-Brown CM, Wheelwright EF, Christie J, McQueen MM. External fixation for tpe-III open tibial fractures. J Bone Joint Surg [Br] 1990;72-B:801-4.

11. Dellinger EP, Miller SD, Wertz MJ, et al. Risk of infection after open fracture of the arm or leg. Arch Surg 1988;123:1320-7.

12. Gustilo RB, Merkow RL, Templeman D. Current concepts review: the management of open fractures. J Bone Joint Surg [Am] 1990;72-A:299-304.

13. Godina M. Early microsurgical reconstruction of complex trauma of the extremities. Plast Reconstr Surg 1986;78:285-920. 
14. Court-Brown CM, McQueen MM, Quaba AA, Christie J. Locked intramedullary nailing of open tibial fractures. J Bone Joint Surg [Br] 1991;73-B:959-64.

15. Tornetta P 3rd, Bergman M, Watnik N, Berkowitz G, Steuer J. Treatment of grade-IIIB open tibial fractures: a prospective, randomised comparison of external fixation and non-reamed loaded nailing. J Bone Joint Surg [Br] 1994;76-B:13-19.

16. Hertel R, Lambert SM, Muller S, Ganz R. On the timing of soft-tissue reconstruction for open fractures of the lower leg. Arch Orthop Trauma Surg 1999;119:7-120.

17. Gopal S, Majumder S, Batchelor AGB, et al. Fix and flap: the radical orthopaedic and plastic treatment of severe open fractures of the tibia. J Bone Joint Surg $[B r]$ 2000;82-B:959-66

18. Jenkinson C, Coulter A, Wright L. Short form 36 (SF36) health survey questionnaire: normative data for adults of working age. BMJ 1993;306:1437-40.

19. Walters SJ, Munro JF, Brazier JE. Using the SF-36 with older adults: a cross-sectional community based survey. Age Ageing 2001;30:337-43.

20. The Euorqol Group. Euroqol: a new facility measurement of health related quality of life. Health Policy 1990;16:199-208.

21. Brazier J, Jones N, Kind P. Testing the validity of Euroqol and comparing it with SF36 health survey questionnaire. Qual Life Res 1993;2:169-80.

22. Kind P, Gudex $\mathbf{C M}$. Measuring health status in community: a comparison of methods. J Epidemiol Community Health 1994;48:86-91.

23. Williams A. The measurement and valuation of health: a chronicle: discussion paper 136. York: Centre for Health Economics, The University of York, 1995

24. Kind P, Dolan P, Gudex C, Williams A. Variations in population health status: results from a United Kingdom national questionnaire survey. BMJ 1998;316:736-41.

25. Behrens FF. Fractures with soft tissue injuries. In: Browner PD, Jupiter JB, Levine AM, et al, eds. Skeletal trauma: fractures, dislocations, ligamentous injuries. Second ed. Philadelphia: W. B. Saunders; 1998:391-418

26. Bondurant FJ, Cotler HB, Buckle R, Miller-Crotchett P, Browner BD. The medical and economic impact of severely injured extremities. J Trauma 1988;28:1270-3.

27. Daniel RK, Taylor GI. Distant transfer of an island flap by microvascular anastomoses: a clinical technique. Plast Reconstr Surg 1973;52:111-17.

28. Chang N, Mathes SJ. Comparison of the effect of bacterial inoculation in musculocutaneous and random pattern flaps. Plast Reconstr Surg 1982;70:1-10.
29. Mathes SJ, Alpert BS, Chang N. Use of the muscle flap in chronic osteomyelitis experimental and clinical correlation. Plast Reconstr Surg 1982;69:815-29.

30. Tu YK, Lin CH, Su JI, Hsu DT, Chen RJ. Unreamed interlocking nail versus external fixator for open type III tibia fractures. J Trauma 1995;39:361-7.

31. Keating JF, O'Brien PJ, Blachut PA, Meek RN, Broekhuyseh M. Locking intramedullary nailing with and without reaming for open fractures of the tibial shaft. J Bone Joint Surg [Am] 1997;79-A:334-41.

32. Mohta M, Sethi AK, Tyagi A, Mohta A. Psychological care in trauma patients Injury 2003;34:17-25

33. Arangio GA, Shannon L, Reed JF 3rd. Reemployment of patients with surgical salvage of open high-energy tibial fractures: an outcome study. J Trauma 1997;42:942-5.

34. Francel TJ, Vander Kolk CA, Hoopes JE, Manson PN, Yaremchuk MJ. Microvascular soft tissue reconstruction of acute open tibial fractures: timing of coverage and long-term functional results. Plast Reconstr Surg 1992;89:478-87.

35. Levy AS, Wetzler M, Lewars M, et al. The orthopaedic and social outcome of open tibial fractures in children. Orthopaedics 1997;20:593-8.

36. Buckley SL, Smith G, Sponseller PD, Thompson JD, Griffin PP. Open fractures of the tibia in children. J Bone Joint Surg [Am]1990;72-A:1462-9.

37. Hoogendoorn JM, Van der Werken C. Grade III open tibial fractures: functional outcome and quality of life in amputees versus patients with successful reconstruction. Injury 2001;32:329-34.

38. Gagum AB, Best AK, Schemitsch EH, et al. Salvage after severe lower extremity trauma: are the outcomes worth the means? Plast Reconstr Surg 1999;103:1212-20.

39. Dougherty PJ. Transtibial amputees from the Vietnam War: twenty-eight year follow-up. J Bone Joint Surg [Am] 2001;83-A:383-9.

40. Hoaglund FT, Jergesen HE, Wilson L, Lamoreux LW, Roberts R. Evaluation of problems and needs of veteran lower limb amputees in the SF bay area during the period 1977-1980. J Rehabil RD 1983;20:57-71.

41. Bosse MJ, Mackenzie EJ, Kellam JF, et al. An analysis of outcomes of reconstruction or amputation after leg-threatening injuries. N Engl J Med 2002;347: 1924-31.

42. Hertel R, Strebel N, Ganz R. Amputation versus reconstruction in traumatic defects of the leg: outcome and costs. J Orthop Trauma 1996;10:223-9. 